\title{
Epstein Barr virus and Cytomegalovirus reactivation in patients with chronic laryngotracheitis
}

\author{
Mary Es Beaver*1 and Fatima Raza ${ }^{2}$ \\ ${ }^{1}$ Texas Voice Center, Houston TX, USA \\ ${ }^{2}$ Texas ENT Specialists, Houston TX, USA
}

\begin{abstract}
Objective: Determine the prevalence of reactivation of Ebstein Barr virus (EBV) and Cytomegalovirus (CMV) in patients with chronic laryngotracheitis (CLTR).

Methods: A retrospective case series of 507 patients presenting with a chief complaint of hoarseness, sore throat, difficulty swallowing, or cough for greater than six weeks was performed. Patients were included if stroboscopic exam showed laryngeal/tracheal inflammation and serology for EBV and CMV was done. SPSS was used to analyze prevalence of elevated IgG to EBV Nuclear Antigen (EBNA), EBV Viral Capsid Antigen (EB VCA), EBV Early Antigen (EBV EA) and CMV $\mathrm{IgG}$ in whole study sample, each symptom group and symptom duration category (1-3 months, 4-6 months, and $>6$ months).

Results: 193 (38\%) patients were EBV EA seropositive with mean titer of 1.81 while $157(33 \%)$ had elevated CMV IgG (mean $=6.1) .48 \%$ of patients with cough had significantly elevated EBV EA IgG while 35\% showed elevated CMV Immunoglobulins. Among difficulty swallowing and sore throat groups, 34\% and 46\% were highly seropositive to EBV EA compared to $30 \%$ and $15 \%$ with elevated CMV IgG. $50 \%$ of the patients in the 4-6 month duration of illness group had elevated EBV EA IgG compared to $42 \%$ and $38 \%$ in 1-3 months and $>6$ months duration respectively.

Conclusion: The prevalence of EBV and CMV reactivation in immunocompetent patients with CLTR is significant, may be more common in the patient with symptoms of intermediate duration, and may indicate reactivation of EBV and CMV as a cofactor in CLTR.
\end{abstract}

\section{Introduction}

The patient presenting with symptoms and signs of chronic laryngeal and tracheal inflammation is a common sight for the otolaryngologist $[1,2]$. Symptoms vary and may include hoarseness, throat clearing, cough, globus, or difficulty swallowing. Signs of laryngeal inflammation include vocal fold edema and erythema, arytenoid edema and erythema, pachydermia, thick mucus, and subglottic erythema. A previous study by the author to evaluate bacterial etiology of chronic laryngotracheitis revealed a 15\% incidence of active Mycoplasma Pneumonia infection and a $24 \%$ incidence of recent Bordetella Pertussis infection in this patient population [3]. This study was conceived to determine potential viral contribution to prolonged airway inflammation to further guide diagnostic testing and patient health counseling. Epstein Barr virus (EBV) has been implicated as a trigger or a primary etiology in syndromes of airway inflammation (granulomatosis polyangiitis), autoimmune diseases, malignancies, pneumonitis in transplant patients, and detected in the patient with chronic cough [4-7]. CMV likewise can cause severe pneumonia in immunocompromised hosts [7]. The EBV viral protein Nuclear antigen 3C (EBNA3C) up regulates cox-2 production by altering the transcription activity of the metastasis suppressor Nm23HI [8]. Elevated cox-2 levels have been found in a variety of inflammatory diseases, premalignant and malignant diseases [9]. Despite a high prevalence rate of EBV and CMV of $80-90 \%$ in the adult population [10-12] and predilection for upper airway infections, little is known about the role of EBV and CMV in patients with chronic laryngeal and tracheal inflammation.

EBV belongs to the gamma-1 herpes virus family. It is a double stranded DNA virus with a toroid shaped protein core that consists of DNA, nucleocapsid, outer envelope and an intervening protein tegument [13]. Herpes viruses that can become latent in lymphocytes and reactivate in times of immunosuppression or stress include EBV, CMV, VZV, HHV-6, and HSV [14-17]. Reactivation, thought to be a result of decreased cellular immunity leads to virally mediated tissue injury that differs according to the viral pathogen. EBV, CMV and HSV are known to cause nosocomial pneumonitis [18].

The common primary EBV infection, known as mononucleosis, causes profound pharyngeal and laryngeal inflammation with sore throat, malaise, fever, and lymphadenopathy. After the primary infection, viral DNA becomes incorporated in lymphocyte DNA and can remain dormant for many years. Immunosuppression or severe stress may lead to viral reactivation, and elevated EBV titers have been detected in transplant patients, elite athletes during strenuous training and even medical interns with sleep deprivation [19-21]. Evidence for EBV DNA shedding in saliva has been found in astronauts during space flight which has corresponded with other markers of immune suppression [22]. It is unknown whether bacterial or other viral upper respiratory infection can induce EBV reactivation thereby increasing morbidity by prolonging symptoms or signs of laryngotracheitis.

Correspondence to: Dr. Mary Es Beaver, Texas Voice Center, Houston TX, USA, Tel: (713) 791-9363; E-mail: drbeaver@TEXASENT.COM

Key words: Epstein Barr Virus, EBV, hoarseness, laryngitis, chronic laryngitis, chronic laryngotracheitis, throat clearing, cough, globus, vocal cord, vocal fold, Cytomegalovirus, difficulty swallowing

Received: March 10, 2017; Accepted: April 05, 2017; Published: April 07, 2017 
EBV specific serological tests have been widely used to differentiate various stages of EBV infection such as acute infection, viral reactivation, and latent infection. The simultaneous presence of $\operatorname{IgG}$ against EBV Early antigen (EBV EA) along with elevated IgG to Epstein Barr nuclear antigen (EBNA) and Epstein Barr viral capsid antigen (EB VCA) has been said to be a marker for EBV reactivation [23]. Early antigen is a cluster of nonstructural viral proteins that are released during viral replication [24]. This study was performed to assess prevalence of EBV reactivation in patients with signs and symptoms of chronic laryngeal and tracheal inflammation. The objectives of this study were to assess the prevalence of serologic evidence for Epstein Barr virus and cytomegalovirus reactivation in patients with signs and symptoms of chronic laryngotracheitis.

\section{Methods}

This is a descriptive epidemiological study that uses retrospectively collected data from medical records of patients diagnosed with chronic laryngotracheitis from July, 2012 - Nov, 2014 at Texas Center for Voice and Swallowing, Houston TX.

Five hundred and seven patients who presented with complaints of cough, difficulty swallowing, hoarseness, sore throat, throat clearing and globus for more than six weeks and who had serology for EBV and CMV, from 07/2012 - 11/2014 were included in this study.

Exemption from IRB review was sought by the New England Institutional Review Board under the following category: "Research involving the collection or study of existing data, documents, records, pathological specimens, or diagnostic specimens, if these sources are publicly available OR if the information is recorded by the Investigator in such a manner that subjects cannot be identified, directly or through identifiers linked to the subjects".

A waiver of authorization was obtained from the New England Privacy Board as study design met the above criteria.

Medical records of the study subjects were reviewed and information about study participant's diagnosis, presenting complaint and its duration, report of EBV and CMV serology was recorded in Microsoft Excel spreadsheets to develop a database specific for this study. Subject data was coded so that human subjects were not identifiable directly or through identifying information. Waiver for individual patient consent for participation in the study was granted by the New England Privacy Board as no patient was contacted during the study and identifying information about subjects was not available and was securely protected in the electronic database.

ELISA testing was used to detect all serologic markers for EBV and CMV. The reported lab threshold for abnormal EBV and CMV immunoglobulins was $>0.9$ units. This was confirmed with Quest Diagnostics, the lab where EBV serology testing was done as well as with Zeus Scientific the manufacturer of ELISA kits for EBV serological markers. A margin of error was added for this study to reduce false positive results; early antigen Ab IgG value > 1.10 was used as a cut off value for a positive result. The sensitivity and specificity of the EBV ELISA are reported to be $82 \%$ and $93 \%$ respectively. The cutoff for a positive result as $>1.10$ was also used for both EBV VCA and EBV NA immunoglobins. Since ELISA kits are intended for the qualitative detection of IgG antibodies to the specific sample, a result of $>5.0$ meant the patients was highly positive for the specific IgG. The results that were highly positive and reported by the lab as $>5$ were assigned a value of 5 for data analysis purposes. The patients with both elevated EBV EA and elevated EBNA/VCA were considered to have had viral reactivation.
A value of CMV $\operatorname{IgG}>3$ was considered as elevated for the purpose of this study as this indicates recent infection.

The Statistical package SPSS 22.0 (SPSS, Inc., Chicago, Illinois) was utilized for data coding and analysis. Descriptive summary statistics of frequency and percentage were calculated for all the variables of presenting complaint, duration of illness, EBV serological markers (Early Antigen Antibody IgG, Nuclear Antigen Antibody IgG, Viral Capsid Antigen Antibody IgG, EBV IgM), and CMV serologic marker (IgG).

Cross tabulation (chi-square test) was used to analyze the distribution of each presenting complaint, duration of illness, EBV Early Antigen Ab IgG seropositivity and CMV seropositivity. Level of significance ( $\mathrm{p}$ - value) was set at 0.05 .

\section{Results}

\section{EBV Early Antigen IgG Serology}

Out of 507 study subjects, 193 (38\%) tested positive for EBV early antigen IgG (>1.10) \%). The mean IgG value of this group was $1.81 \mathrm{U}$ which was a significant elevation from the lab standard of a negative value of $<0.9$.

\section{EBV Nuclear Antigen IgG Serology}

Most of the study patients tested positive for EBV nuclear antigen with a mean value of 4.64 . One hundred and twenty five $(29 \%)$ of those subjects with elevated EBV NA had IgG value greater than 5. 61 subjects(49\%) and 121 subjects (97\%) were also found to be seropositive for early antigen IgG and viral capsid antigen IgG respectively.

EBV IgM Serology: 12 patients (2.3\%) were positive for EBV IgM indicating acute infection.

\section{Viral Capsid Antigen (VCA) IgG Serology}

Four hundred and fifty one (89\%) subjects were reported to be seropositive for EBV viral capsid antigen IgG indicating previous EBV infection. The mean IgG value for this group was 3.93. 110 subjects had IgG value greater than 5 .

\section{IgG Serology}

Two hundred and forty five (48.3\%) patients had elevated CMV IgG with a mean value of 6.09 . One hundred and fifty seven of these subjects with elevated CMV IgG had value greater than 3 thus depicting recent infection (Table 1).

\section{Analysis of presenting complaint and EBV and CMV serological marker}

Hoarseness was the most commonly reported presenting complaint. A total of 199 study subjects listed hoarseness as their chief physical complaint. Out of these 79 (39.7\%) were found to be seropositive for early antigen IgG and nuclear antigen IgG and 59 (30\%) had CMV IgG values greater than 3 (Table 2). Mean IgG values for this group of

Table 1. EBV/CMV Serology
\begin{tabular}{|c|c|c|c|}
\hline Serological Marker & Positive & Negative & Mean \\
\hline Early Antigen IgG & $193(38 \%)$ & $314(61.9 \%)$ & 1.81 \\
\hline Nuclear Antigen IgG & $429(84.6 \%)$ & $52(10.3 \%)$ & 4.64 \\
\hline Viral Capsid Antigen IgG & $451(89 \%)$ & $44(8.7 \%)$ & 3.93 \\
\hline EBV IgM & $12(2.3 \%)$ & $452(89.1 \%)$ & 1.39 \\
\hline CMV IgG & $245(48.3 \%)$ & $219(43.8 \%)$ & 6.09 \\
\hline
\end{tabular}


subjects with hoarseness were $1.8 \mathrm{U}$ and $5.59 \mathrm{U}$ respectively. 47 patients were positive for both EBV and CMV seromarkers.

Difficulty swallowing was reported as the chief presenting complaint by 73 study subjects. Out of these $33.8 \%$ (23) had a positive result for EBV early antigen ELISA testing while 22 (30\%) showed CMV IgG elevation greater than 3. The mean IgG values for this group were 2.08 and 6.72 respectively. 13 had elevated immunoglobulins for both EBV and CMV.

87 patients reported cough as their major symptom. $48.2 \%$ of these patients were positive for early antigen IgG with a mean titer of 2.03. $35 \%$ were seropositive to CMV with a mean titer of 4.98 .

58 patients listed sore throat as main presenting complaint. $46.6 \%$ of these were positive for EBV early antigen Ab IgG, with a mean titer of 1.54 (Table 2 and Table 3 ).

Cross tabulation analysis with chi square tests were used to compare the duration of illness to the early antigen serology. There was a significantly higher rate of elevated EBV early antigen among patients with symptoms of 4-6 months duration. Their respective $p$ values were 0.01 and 0.02 . No other comparisons were significant (Table 4).

\section{Discussion}

Chronic laryngotracheitis is a commonly diagnosed condition by family practitioners, internists, otolaryngologists and gastroenterologists. Despite its common occurrence the management remains a challenge for physicians owing to non-specific nature of symptoms, which makes it a well investigated topic [25]. Various etiologies and causative factors have been described in previous research.

Though infectious agents are recognized as potential pathogens leading to chronic inflammation of larynx, there are few studies reporting the prevalence of specific viruses/bacteria/fungi among patients presenting with symptoms of chronic laryngotracheitis. This study reported that $38 \%$ of the study participants presenting with symptoms of CLTR turned out to be seropositive for IgG against

Table 2. Prevalence of EBV/CMV in various chief complaints

\begin{tabular}{|c|c|c|c|c|c|c|}
\hline Symptom & $\begin{array}{c}\text { Number } \\
\text { of Patients } \\
\text { (N) }\end{array}$ & $\begin{array}{c}\text { Early Ag } \\
\text { IgG Pos }\end{array}$ & $\begin{array}{c}\text { Nuc Ag } \\
\text { IgG Pos }\end{array}$ & $\begin{array}{c}\text { VCA IgG } \\
\text { Pos }\end{array}$ & $\begin{array}{c}\text { CMV IgG } \\
<\mathbf{3}\end{array}$ & $\begin{array}{c}\text { CMV IgG } \\
>\mathbf{3}\end{array}$ \\
\hline Hoarseness & 199 & $79(39.7 \%)$ & $\begin{array}{c}173 \\
(86.9 \%)\end{array}$ & $\begin{array}{c}182 \\
(90.9 \%)\end{array}$ & $40(20.4 \%)$ & $59(30.1 \%)$ \\
\hline $\begin{array}{c}\text { Difficulty } \\
\text { swallowing }\end{array}$ & 73 & $23(33.8 \%)$ & $65(95.5 \%)$ & $68(93.2 \%)$ & $11(15.1 \%)$ & $22(30.1 \%)$ \\
\hline Cough & 87 & $41(48.2 \%)$ & $78(91.7 \%)$ & $83(97.6 \%)$ & $15(17.2 \%)$ & $31(35.6 \%)$ \\
\hline Sorethroat & 59 & $27(46 \%)$ & $49(83 \%)$ & $51(86.4 \%)$ & $10(17.2 \%)$ & $9(15.5 \%)$ \\
\hline
\end{tabular}

Table 3. Mean titers of EBV EA, EBV NA AND EBV CA among chief complaint groups

\begin{tabular}{|c|c|c|c|}
\hline Symptom & Mean Early Ag IgG & Mean Nuc Ag IgG & Mean VCA IgG \\
\hline Hoarseness & 1.8 & 4.61 & 3.8 \\
\hline $\begin{array}{c}\text { Difficulty } \\
\text { swallowing }\end{array}$ & 2.08 & 4.93 & 4.01 \\
\hline Cough & 2.03 & 4.44 & 4.01 \\
\hline Sorethroat & 1.54 & 4.48 & 3.66 \\
\hline
\end{tabular}

Table 4. Prevalence of EBV/CMV in Duration of Illness groups

\begin{tabular}{|c|c|c|c|c|}
\hline $\begin{array}{c}\text { Duration of } \\
\text { symptoms }\end{array}$ & $\begin{array}{c}\text { Early Ag IgG } \\
\text { Pos }\end{array}$ & $\begin{array}{c}\text { Early Ag IgG } \\
\text { Neg }\end{array}$ & CMV IgG Pos & CMV IgG Neg \\
\hline 6 Mo & $114(38.8 \%)$ & $175(59.5 \%)$ & $81(34.1 \%)$ & $156(65.8 \%)$ \\
\hline $\mathbf{4}$ - 6 Mo & $39(50 \%)$ & $38(48.2 \%)$ & $23(44.2 \%)$ & $29(55.7 \%)$ \\
\hline $\mathbf{1 - 3}$ Mo & $49(42.6 \%)$ & $64(55.7 \%)$ & $33(34.3 \%)$ & $63(65.6 \%)$ \\
\hline
\end{tabular}

EBV early antigen suggesting a reactivation. "Reactivation" has been defined as an elevation of antibodies to early antigen in the presence of antibodies to EBNA [26]. Early antigen positivity without elevation of IgG to capsid or nuclear antigen is an indication of active infection but in the presence of elevated IgG's to EB NA or EBVCA is an indication of viral reactivation $[24,26]$. When EBV reactivation is detected in septic ICU patients, those patients have a longer length of stay and their course is complicated by significantly more bacterial and fungal infections [15] which implicates the immunocompromised state of the patient with sepsis but also points to the viral opportunistic behavior.

In our study approximately $90 \%$ of the subjects tested positive for IgG antibodies to EBNA (Nuclear Antigen) as well as VCA (Viral Capsid Antigen) indicating previous infection which is similar to other published rates of previous EBV exposure [24, 27]. This prevalence of EBV in our cohort also correlates with the national statistics of population prevalence of EBV exposure stated by CDC [26] as well as by Chijioke et al. [28]. In this study a significant rate of elevation of EBV EA (50\%) was detected in the patients with symptoms of intermediate duration (4-6 months). Our significant rate of EBV reactivation in chronic laryngotracheitis brings up the question of whether EBV is the primary cause of the inflammation or is merely a cofactor. EBV reactivation has been associated with diminished cell mediated immunity thus enhancing the risk of coinfection with other microorganisms [29]. It is possible that the EBV reactivation detected in our patients was an opportunistic event coinciding with other viral or bacterial upper airway infections in these patients. Further study is needed to determine rates of multiple organism infections in these patients.

EBV IgM appears within the first week of primary acute infection and declines soon after virus is cleared. IgG levels may persist for months or years in few cases making it difficult to differentiate new infection from previous immune response [30]. With the addition of EBV EA testing it is possible to diagnose reactivation which may be a cofactor in potentiation of upper airway inflammation. Another valuable advantage of early serological investigation is in detecting high EBV IgM indicating a contagious case, counseling the patient about the need for quarantine and expected duration of symptoms and avoiding the unnecessary use of antibiotics after the acute phase of infection has passed (Figure 1).

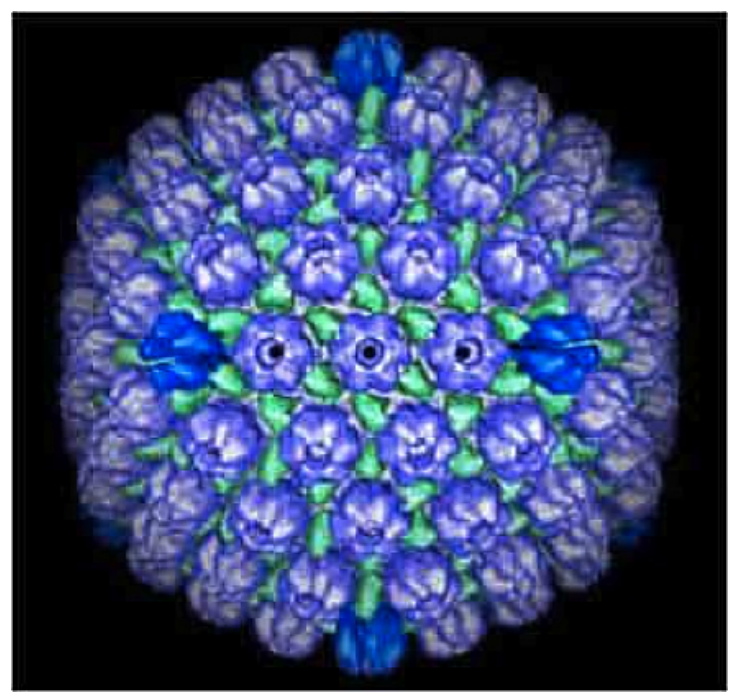

Figure 1. EB Virus 


\section{Conclusion}

EBV titers and CMV titers are a worthwhile investigation in the patient with CLTRThe prevalence of EBV and CMV reactivation in immunocompetent patients with CLTR is significant, may be more common in the patient with symptoms of intermediate duration, and may indicate reactivation of EBV and CMV as a cofactor in CLTR by potentiatiating upper airway inflammation and prolonging patient symptoms.

${ }^{*}$ Presented at the Fall Voice Conference, Philadelphia PA, October 2015

\section{References}

1. Mau T (2010) Diagnostic evaluation and management of hoarseness. Med Clin North Am 94: 945-960. [Crossref]

2. Roy N, Merrill RM, Gray SD, Smith EM (2005) Voice disorders in the general population: prevalence, risk factors, and occupational impact. Laryngoscope 115: 1988-1995. [Crossref]

3. Beaver ME, Karow CW (2009) Incidence of Seropositivity to Bordetella Pertussis and Mycoplasma Pneumoniae Infection in Patients With Chronic Laryngotracheitis. Laryngoscope. 119:1839-1843. [Crossref]

4. McManus TE, Marley AM, Baxter N, Christie SN, Elborn JS, et al. (2008) High levels of Epstein-Barr virus in COPD. Eur Respir J 31: 1221-1226. [Crossref]

5. Lidar M, Lipschitz N, Langevitz P, Barzilai O, Ram M, et al. (2009) Infectious serologies and autoantibodies in Wegener's granulomatosis and other vasculitides: novel associations disclosed using the Rad BioPlex 2200. Ann N Y Acad Sci. 1173:649-657. [Crossref]

6. Otsuka E, Miyazaki Y, Moriyama K, Uno N, Kashima K, et al. (1999) EpsteinBarr virus associated Richter's syndrome accompanied by interstitial pneumonia RinshoKetsueki. 40:402-407. [Crossref]

7. Xuan L, Jiang X, Sun J, Zhang Y, Huang F,et al. (2013) Spectrum of Epstein-Barr virusassociated diseases in recipients of allogeneic hematopoietic stem cell transplantation. Transplantation. 96:560-566. [Crossref]

8. Kaul R, Verma SC, Murakami M, Lan K, Choudhuri T, Robertson ES (2006) Epstein-Barr Virus Protein Can Upregulate Cyclo-Oxygenase-2 Expression through Association with the Suppressor of Metastasis Nm23-H1. Journal of Virology 80: 1321-1331. [Crossref]

9. Cao Y, Prescott SM (2002) Many actions of cyclooxygenase-2 in cellular dynamics and in cancer. J Cell Physiol 190: 279-286. [Crossref]

10. Gärtner B, Preiksaitis JK (2010) EBV viral load detection in clinical virology. J Clin Virol 48: 82-90.[Crossref]

11. Kutok JL, Wang F (2006) Spectrum of Epstein-Barr virus-associated diseases. Annu Rev Pathol 1: 375-404. [Crossref]

12. Lancini D, Faddy HM, Flower R, Hogan C (2014) Cytomegalovirus disease in immunocompetent adults. Med J Aust 201: 578-580. [Crossref]

13. [No authors listed] (1997) Proceedings of the IARC Working Group on the Evaluation of Carcinogenic Risks to Humans. Epstein-Barr Virus and Kaposi's Sarcoma Herpesvirus/Human Herpesvirus 8. Lyon, France, 17-24 June 1997. IARC Monogr Eval Carcinog Risks Hum 70: 1-492. [Crossref]
14. Ansell SM, Li CY, Lloyd RV, Phyliky RL (1999) Epstein-Barr virus infection in Richter's transformation. Am J Hematol 60: 99-104.[Crossref]

15. Walton AH, Muenzer JT, Rasche D, Boomer JS, Sato B, et al. (2014) Reactivation of multiple viruses in patients with sepsis. PLoS One 9: e98819.[Crossref]

16. Bruynseels P, Jorens PG, Demey HE, Goossens ,Pattyn SR, et al. (2003) Herpes Simplex virus in the respiratory tract of critical care patients: a prospective study. Lancet 362:1536-1541. [Crossref]

17. Cook CH, Martin LC, Yenchar JK, Lahm MC, McGuinness B, et al. (2003) Occult herpes family viral infections are endemic in critically ill surgical patients. Crit Care Med 31: 1923-1929. [Crossref]

18. Chiche L, Forel JM, Papazian L (2011) The role of viruses in nosocomial pneumonia Curr Opin Infect Dis24: 152-156. [Crossref]

19. Peter N. Uchakin, David C. Parish, Francis C. Dane, et al. (2011) Fatigue in Medical Residents Leads to Reactivation of Herpes Virus Latency. Interdisciplinary Perspectives on Infectious Diseases. Article ID 571340, 7.

20. Rouce RH, Louis CU, Heslop HE (2014) Epstein-Barr virus lymphoproliferative disease after hematopoietic stem cell transplant. Curr OpiHematol21: 476-481. [Crossref]

21. Bakker NA, Verschuuren EA, Erasmus ME, Hepkema BG, Veeger NJ, et al (2007) Epstein-Barr virus-DNA load monitoring late after lung transplantation: a surrogate marker of the degree of immunosuppression and a safe guide to reduce immunosuppression. Transplantation 83: 433-438. [Crossref]

22. Mehta SK, Laudenslager ML, Stowe RP, Crucian BE, Sams CF,et al. (2014) Multiple latent viruses reactivate in astronauts during Space Shuttle missions. Brain Behav. Immun. 41: 210-217. [Crossref]

23. Sumaya CV (1977) Endogenous reactivation of Epstein-Barr virus infections. J Infect Dis 135: 374-379. [Crossref]

24. Crowley A, Connell J, Schaffer K, Hall W, Hassan J (2012) Is There Diagnostic Value in Detection of Immunoglobulin G Antibodies to the Epstein-Barr Virus Early Antigen? Bio Research. 1: 291-296.

25. Dworkin JP (2008) Laryngitis: types, causes, and treatments. Otolaryngol Clin North Am 41: 419-436, ix. [Crossref]

26. http://www.cdc.gov/ncidod/diseases/ebv.htm

27. Bauer G (1995)The rational basis for efficient Epstein-Barr virus (EBV) serology. Clin Lab. 41:623-634.

28. Chijioke O1, Azzi T, Nadal D, Münz C (2013) Innate immune responses against Epstein Barr virus infection. Journal of Leukocyte Biology 94: 1185-1190. [Crossref]

29. Glaser R, Pearson GR, Bonneau RH, Esterling BA, Atkinson C, et al. (1993) Stress and the memory T-cell response to the Epstein-Barr virus in healthy medical students. Health Psychol 12: 435-442. [Crossref]

30. Waites KB, Talkington DF (2004) Mycoplasma pneumoniae and its role as a human pathogen. Clin Microbiol Rev 17: 697-728, table of contents.[Crossref]

31. Aoki F (2003) Contemporary antiviral drug regimens for the prevention and treatment of orolabial and anogenital herpes simplex virus infection in the normal host: Four approved indications and 13 off-label uses. Can JInfect Dis 14:17-27.[Crossref]

Copyright: (C2017 Beaver ME. This is an open-access article distributed under the terms of the Creative Commons Attribution License, which permits unrestricted use, distribution, and reproduction in any medium, provided the original author and source are credited. 